\section{Leprosy: is the strategy wrong?}

Authoritative opinion claims that there has been a failure to provide treatment for most of the world leprosy patients and to control the spread of the disease. But sulphones provide a cheap and practical form of treatment and also prevent transmission of leprosy, writes C. L. Crawford, of the Department of Anatomy and Embryology, University College, London.

IN 1873 the Norwegian Armaeur Hansen found bacteria in the tissues of leprosy patients and thus established the infectious nature of the disease. Today the World Health Organisation (WHO) estimates there are 10.8 million people with the disease, of whom only about $18 \%$ are receiving any treatment. Although information is limited it also concludes (Bull. Wld. Hlth. Org., 46, 523 ; 1972) that there has not been any improvement in controlling the spread of the disease over the past five years. The British Leprosy Relief Association (LEPRA) claim that there are as many as 20 million patients. Browne and Davey, two of the most experienced leprologists, (writing this year in Leprosy Review), conclude that existing methods have failed to reduce the in cidence of the disease, and Ambrose Nature, 248, 370; 1974) states that leprosy is increasing in South Asia.

Leprologists stress the unknown facts about the disease; the bacteria cannot be cultivated so a vaccine cannot be developed, and the mode of transmission and the incubation period are unknown. Faced with this lack of knowledge and the pessimism of authoritative opinion, the outlook seems hopeless both for success in preventing the spread of the disease and for the patient's chances of obtaining treatment. But the efficacy of the sulphone in providing a cheap and practical form of treatment and in prevention has been grossly neglected.

The difficulty in culturing $\mathrm{Myco}$ bacterium leprae could, in fact, be seen as a potential advantage in an attack on the disease. Mycobacterium leprae is confined to humans and must therefore exist outside the body only for very short periods. There is no known animal reservoir of infection or vector to spread the disease and transmission takes place only between humans. Probably only a proportion of leprosy patients are responsible for

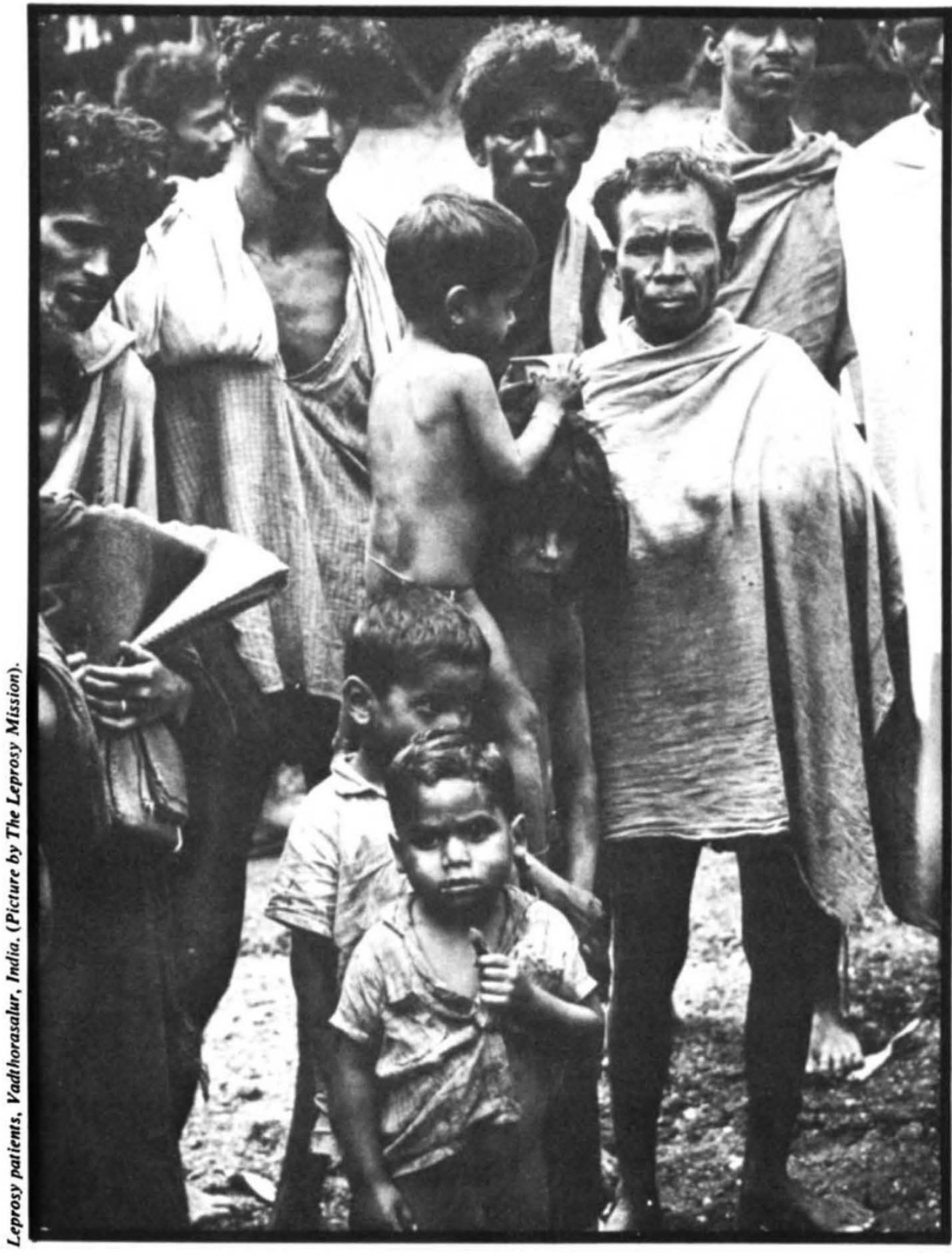

transmitting the disease. This multibacillary or lepromatous group may be as low as $10 \%$ in some parts of the world and constitutes the reservoir of infection. Also only one in ten of the exposed population, at the most, acquire the disease even in the absence of control measures. If transmission could be interrupted in susceptible people, the disease would decline, as indeed it did in Norway in the last century by a policy of segregation. Also, once eradicated from any country it has never returned. A vaccine is not essential for eradication as the disease has already disappeared from many countries. The transmission of yaws has been successfully interrupted without the bacteria being cultivated or a vaccine developed, by treating patients with penicillin.

The sulphones are the main drugs used in the treatment of leprosy. The experimental multiplication of $M$. leprae in mice is inhibited if $M$. leprae from patients who have received more than three months of sulphone treatment are injected, suggesting that such bacteria are no longer viable. It may thus be that patients with leprosy are no longer infectious after a few months of treatment, and sulphones may have an important role in preventing the spread of the disease as well as in treatment. Sulphones have been used for the past 25 ycars and it is essential to determine if they have had any effect in preventing transmission of leprosy.

Any successful preventative measure against leprosy will be shown by a fall in the number of new cases or in the incidence rate; the total number of cases (or 'prevalence' rate) will change much more slowly, because of the inclusion of patients who are already crippled. If the majority are of this type, the prevalence may hardly change at all over a period of years, even though transmission may have been completely interrupted, because leprosy patients can live a long time. 
The life expectancy of untreated lepromatous leprosy in Hansen's time was about 10 years; now, with sulphones, it is the same as in the general population. Thus, the 'prevalence' may actually rise in a community treated with sulphones. It is therefore very surprising that the WHO should attempt to draw conclusions about the spread of the disease from the figure of 10.8 million, which is a prevalence estimate. No attempt has been made to obtain information about incidence rates, and even the estimate of the total number of cases is based on very questionable assumptions. Of the 10.8 million, 2.5 million are actually registered; 0.5 million of these are cured or arrested. In each country, to make allowance for unknown cases, a percentage of the registered cases was calculated depending on the efficiency of case finding. This varied between $25 \%$ and $300 \%$ of the registered cases. This total was added to the 2.5 million registered cases to make up the total of 10.8 million. There must, however, be doubts about the value of figures arrived in such a haphazard way. Where accurate figures of leprosy patients are available, as in Rumania, Cyprus and Libya, it has been shown that the WHO has exaggerated the true figure by from 10 to 50 times. In commenting on the WHO errors in the Cyprus figures, the Cyprus Director-General of Health emphasised that all the patients were old ones and no new cases had occurred in 1970, thus confirming the danger of drawing conclusions about the spread of the disease from prevalence figures. Countries which do have information about incidence rates, such as Okinawa, Hong Kong, New Guinea, Japan and Solomon Islands, Rumania and Cyprus, have all shown a decline. Although their figures will not be completely accurate, they are preferable to the WHO method of assessing the problem.

Most of the countries mentioned have a small leprosy problem. The most accurate information about incidence rates in highly endemic areas has come about in the following way. As no leprosy vaccine is available, $B C G$ vaccine against the similar tubercle bacillus has been used to determine whether it has a protective effect againt leprosy. Trials have taken place in Uganda, Burma and New Guinea under the auspices of various research councils, and two trials have also been carried out in India using sulphones for their protective or chemoprophylactic effect by giving them to healthy people. All the trials were controlled by including a group similar in age range which was not protected with BCG or sulphones. At the start of trials the population was sur- veyed, the leprosy cases were excluded and then new cases were recorded at repeated intervals of between one and two years. Thus, an annual incidence rate can be deduced and the control group will reveal the trend of the disease in these areas, which were deliberately chosen because of the serious leprosy problem.

The results of the $\mathrm{BCG}$ trial in Uganda and the two chemoprophylactic trials in India are shown in Tables 1 and 2. All the control groups shows a striking decline in the incidence of leprosy. These two trials took place in communities where sulphones are available to treat patients and, in contrast, the incidence of leprosy in New Guinea did not decline, staying constant at 6 per 1,000 per year from 1964 to 1969; sulphones were not available in this area until late in 1967. Therefore, the most likely explanation of the declining incidence rates is that sulphones given to leprosy patients kill $M$. leprae in a short enough time to interrupt transmission of the disease, thus confirming the experimental findings. The figures for new lepromatous cases are even more dramatic. In two of the areas not a single case was recorded in the controls and in the third the number fell from 11 to 2 . Thus, the reservoir of infection has been virtually removed and this makes prospects of eradication bright. The chemotherapeutic and BCG trials were started over ten years ago yet delay in publishing the results fully and in coming to a conclusion about their efficacy has meant that a really effective method of prevention and eradication with sulphones is not being put into practice. If there is still any doubt about the conclusions to be drawn from these trials, these areas could be resurveyed and the incidence rates recorded in the same age groups as those of ten years ago. There is other evidence based on outpatient incidence rates from two areas of India, Zambia and Uganda and from prevalence rates over a long period in Northern Nigeria, and former French Equatorial Africa (Gabon, Chad, Central African Republic and CongoBrazzaville). All these have been summarised with my conclusions of the BCG and chemoprophylactic trials previously (Lancet, ii 1375, 1971; i, 1186, 1972; Trop. Doct., 3, 137, 1973). Also there is recent evidence of a decline in incidence in Burma and Thailand. Yet Ambrose, Davey and Browne have not mentioned these nor produced any quantitative information to support their own case.

If chemotherapy with sulphones does prevent the spread of the disease then treatment and prevention can be achieved by the same measure, the administration of the drugs to leprosy patients, especially those who are bacteriologically positive. Also by offering to the patients an incentive to attend for treatment, the affected group in the community is automatically brought under supervision, an immense practical advantage over other methods of prevention such as BCG and chemoprophylaxis, which depend on finding healthy contacts of patients. The main sulphone is dapsone which is extremely cheap, costing only $10 \mathrm{p}$ a year for each patient, and is easily administered by mouth once a week. Drug resistance is very rare, of the order of 3 per 5,000 lepromatous patients, and it has a wide margin of safety for toxic effects. Thus, mass treatment is practical and economically feasible if given in villages by

Table 1 Annual incidence of leprosy per 1,000 in control and BCG groups in the BCG leprosy trial in Uganda

\begin{tabular}{ccccccc}
\hline & $\begin{array}{c}\text { Population } \\
\text { examined }\end{array}$ & $\begin{array}{c}\text { Control } \\
\text { No. with } \\
\text { leprosy }\end{array}$ & $\begin{array}{c}\text { Annual } \\
\text { incidence }\end{array}$ & $\begin{array}{c}\text { Population } \\
\text { examined }\end{array}$ & $\begin{array}{c}\text { No. with } \\
\text { leprosy }\end{array}$ & $\begin{array}{c}\text { Annual } \\
\text { incidence }\end{array}$ \\
1964 & 8,071 & 89 & 5.5 & 8,091 & 18 & 1.1 \\
1966 & 9,036 & 54 & 3.0 & 9,052 & 1 & 0.05 \\
1968 & 9,036 & 31 & 1.7 & 9,052 & 8 & 0.45
\end{tabular}

The incidence rate has been halved to give the annual incidence as there is an interval of two years between each survey.

Table 2 Annual incidence of leprosy per 1,000 in Andra Pradesh, India, in controls and chemoprophylactic groups: $A$, under 25 years of age; $B$, over 25 years of age

\begin{tabular}{|c|c|c|c|c|c|c|}
\hline & & Controls & $A$ & Protected & th Sulphon & (Dansone) \\
\hline & Population & No. with & Annual & Population & No. with & Annual \\
\hline & examined & leprosy & incidence & examined & leprosy & incidence \\
\hline 1965 & 11,270 & 54 & 4.79 & 11,452 & 29 & 2.53 \\
\hline 1966 & 12,124 & 65 & 5.36 & 11,900 & 14 & 1.17 \\
\hline 1967 & 12,116 & 37 & 3.01 & 12,157 & 9 & 0.74 \\
\hline 1968 & 12,931 & 36 & 2.78 & 12,754 & 3 & 0.24 \\
\hline & & Controls & & Protected & th Sulphon & (Dapsone) \\
\hline & Population & No. with & $\begin{array}{c}\text { Annual } \\
\text { incidence }\end{array}$ & Population & No. with & Annual \\
\hline 1965 & 8,104 & 90 & 11.10 & 7,851 & 91 & 11.59 \\
\hline 1966 & 7,758 & 67 & 8.63 & 7,758 & 62 & 7.95 \\
\hline 1967 & 7,337 & 38 & 5.17 & 7,511 & 45 & 5.9 \\
\hline 1968 & 7,311 & 29 & 3.9 & 7,282 & 34 & 4.6 \\
\hline
\end{tabular}


auxiliary staff who have been trained in diagnosis and treatment.

One area where this approach has been developed most widely is in northern Nigeria and was initiated by Ross. He carried out surveys, trained auxiliary staff and set up outpatient clinics in villages. Patients accepted this approach enthusiastically, whereas before there had been a poor response to treatment based on the leprosarium. In one area, 639 new patients appeared for treatment within 3 months of opening the clinics. There was little fear of stigma against the disease and Ross comments: "There is a degree of shame attached to infection by the disease. Nevertheless, leprosy is tolerated in village and social life and any fear of detection has been associated with the dread of being segregated which means separation from one's family". By 1968 there were 2,000 outpatient clinics throughout the northern region and most patients had access to treatment at an early stage. Unfortunately, few countries adopted such an approach so comprehensively; in many the leprosarium remains the only place where treatmenit can be obtained, patients have to travel long distances and they fear segregation. The numbers on treatment have remained low for these reasons and not because of lack of money as LEPRA claims in its advertisements. The cost of maintaining patients in institutions is enormously high and measures such as reconstructive surgery have added to the financial burden, making even less money available for work in outpatient clinics. Also, diagnosis is late; patients come late in the course of the disease and thus many are crippled and hence do not benefit from dapsone treatment.

Voluntary agencies in Europe collect more than $£ 2$ million annually for leprosy work, but most is still spent on institutional care-in May 1973, for example, the Sunday Times published an illustrated article showing the plight of severely crippled leprosy patients in India. At the same time LEPRA appealed for money. $£ 20,000$ was collected and in a letter to the Sunday Times on December 13, 1973, the Directior of LEPRA gave details of how this money was to be spent. All of it was to be used on institutional care, accommodation and food, and on enabling patients to learn a trade such as footwear and cloth making; little money will go to curing and preventing the disease. As most of the patients are already crippled they cannot benefit from dapsone treatment. While there is sympathy for these patients' needs, surely the bulk of the money should go to prevention and cure with sulphones, which LEPRA claims is its aim.

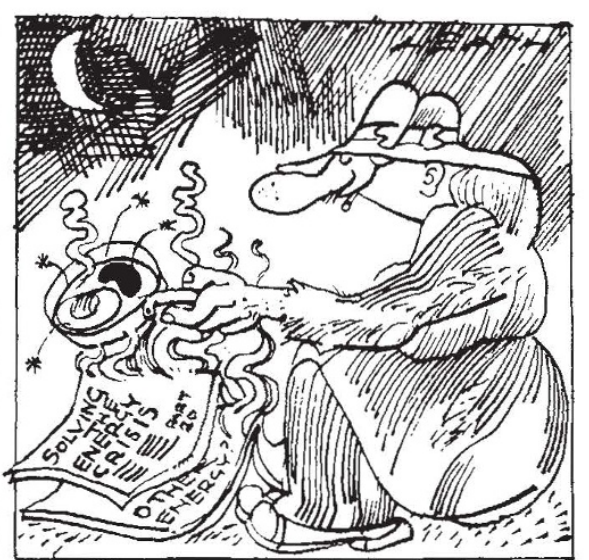

\section{Accounting for energy}

Dr Malcolm Slesser, Director of the Energy Studies Unit, Strathclyde University, sets out the basic principles of energy analysis.

I F economics is the science of scarcity 1 and substitution, energy analysis is no more than the application of economic theory to the one commodity in ultimate limitation on Earth-thermodynamic potential. Perhaps the greatest conceptual difference between economics, as we know it today, and energy analysis lies in the 'system boundary'. Economics sets up a boundary around the system of interest; in energy analysis the system boundary is the whole planet.

Within the framework of economic thought, the economic process will automatically stimulate the development of another energy resource as one resource is depleted and its marginal costs rise. In effect, economics treats the world as a closed system having access to limitless amounts of energy, whose acquisition takes only time, capital labour and technology. On the face of it, it is a good deal easier to justify the position of the economists than that of the energy analysists, but it can be looked at another way.

Any production process, such as building a road or manufacturing pigiron can only succeed if we inject capital, labour, materials and energy. Considering the properties of these inputs, capital is no more than labour, materials, capital and energy invested at an earlier time. If one goes on to examine every one of the inputs to any process one finds that these inputs are themselves the outcome of a process involving capital, labour, materials and energy. Indeed, the process of network analysis can go back and back until we find that the materials are ores in the ground or produce on the land and the energy is hydrocarbon locked in the
Earth or in deuterium atoms in a highly dilute state in the oceans; labour is mankind and capital has disappeared.

Although both energy and materials are mined and utilised, they have very different features. Materials are never destroyed; the iron molecule in iron ore is still an iron molecule when it is turned into steel and when it ultimately ends up as rust. Moreover, there can never really be a shortage of ores, since the oceans contain very large quantities. We are, however, long past that stage of global development at which ores can be obtained at sufficient rates simply by men labouring with picks and shovels. The energy required to win increasingly depleted ores and turn them into concentrated form will rise to enormous values. It is not the scarcity of the ores that is the problem.

When this thinking is applied to the two examples of making pig-iron and road building, it is certainly conceivable that, given enough poor and willing citizens, a motorway could be constructed by human labour alone. But no amount of human sweat can turn iron ore into iron, or iron into sophisticated machine tools. Though there is a well understood marginal energy cost for labour, so that the two can substitute one for the other to some extent, in the last analysis, energy does what labour cannot do. It carries out processes of transformation involving a decrease in entropy. Energy is irretrievably degraded once it has been used. All energy finishes up as waste heat, and must eventually be dissipated to the surrounding space. Labour, by contrast, is renewable and can also be upgraded through such processes as education and training. Also, as development has proceeded, labour, except in its most skilled forms, has become a surplus commodity in the greater part of the world.

Accordingly, energy analysts believe that it makes sense to measure the cost of the things done, not in money, which is after all nothing more than a highly sophisticated value judgement, but in terms of thermodynamic potential. On the other hand it is widely recognised amongst energy analysts that, as R. S. Berry has stated so succinctly, "if economists in the market place were to determine their shortages by looking further and further into the future, these estimates would come closer and closer to the estimates made by their colleagues, the thermodynamicists".

As energy analysis is concerned with the amount of global energy stock which must be sequestered to make a good or service, it is not enough to assess the amount of oil consumed to heat a house. What is of interest is the total amount of oil in the ground, to- 